OPEN ACCESS

Edited by:

Xiaofang Xing,

Peking University Cancer

Hospital, China

Reviewed by:

Regine Schneider-Stock,

University of Erlangen

Nuremberg, Germany

Lin Wang,

New York University, United States

${ }^{*}$ Correspondence:

Liang Qiao

liang.qiao@sydney.edu.au

Fang Xiao

fangxiao@csu.edu.cn

tThese authors have contributed equally to this work

Specialty section:

This article was submitted to Gastrointestinal Cancers,

a section of the journal

Frontiers in Oncology

Received: 02 February 2020

Accepted: 11 May 2020

Published: 30 June 2020

Citation:

Liang Y, Liang Q, Qiao L and Xiao F (2020) MicroRNAs Modulate Drug Resistance-Related Mechanisms in

Hepatocellular Carcinoma.

Front. Oncol. 10:920.

doi: 10.3389/fonc.2020.00920

\section{MicroRNAs Modulate Drug Resistance-Related Mechanisms in Hepatocellular Carcinoma}

\author{
Yuehui Liang ${ }^{1+}$, Qi Liang ${ }^{2+}$, Liang Qiao ${ }^{3 *}$ and Fang Xiao ${ }^{1 *}$ \\ ${ }^{1}$ Department of Health Toxicology, Xiangya School of Public Health, Central South University, Changsha, China, \\ ${ }^{2}$ Department of Radiology, The Third Xiangya Hospital, Central South University, Changsha, China, ${ }^{3}$ Storr Liver Center, \\ Westmead Institute for Medical Research, University of Sydney and Westmead Hospital, Westmead, NSW, Australia
}

Primary liver cancer [hepatocellular carcinoma $(\mathrm{HCC})$ ] is one of the most common malignant tumors worldwide, causing serious health threats because of its high morbidity and mortality, rapid growth, and strong invasiveness. Patients with HCC frequently develop resistance to the current chemotherapeutic drugs, and this is largely attributed to the high-level heterogeneity of the tumor tissue. MicroRNAs (miRNAs) are a group of master regulators for multiple physiological and pathological processes and play important roles in the tumorigenesis. More recent studies have indicated that miRNAs also play a non-negligible role in the development of drug resistance in liver cancer. In this review, we summarize the data from the latest studies on the mechanisms of drug resistance in liver cancer, including autophagy, membrane transporters, epithelial-mesenchymal transitions (EMTs), tumor microenvironment, and genes and proteins that are associated with apoptosis. The data herein will provide valuable information for the development of novel approaches to tackle drug resistance in the management of liver cancer.

Keywords: microRNAs, drug resistance, hepatocellular carcinoma, autophagy, tumor microenvironment

\section{INTRODUCTION}

Primary liver cancer is one of the most common malignant tumors in the worldwide and is a serious health threat to humans because of its high morbidity and mortality, rapid growth, and strong invasiveness (1). According to the global cancer statistics, liver cancer ranks the second leading cause of cancer-related death, and hepatocellular carcinoma (HCC) accounts for 70-90\% of primary liver cancer (2). About 850,000 new cases of HCC are diagnosed worldwide every year, and the number is still on the rise (3). Clinically, surgical resection is the first choice for the treatment of early primary liver cancer, but this treatment approach carries high recurrence rate and high rate of postsurgery metastasis, because most HCC patients are generally diagnosed at the advanced stage, and only palliative treatments such as chemotherapy can be used for treatment. Although chemotherapy may help delay or avoid tumor recurrence in the short term, its long-term role in extending patient survival is very limited (4).

It is well-known that HCC can rapidly develop resistance to the currently available chemotherapeutic drugs $(5,6)$. In the management of cancer patients, drug resistance is a critical hurdle for successful treatment. It has been reported that resistance to chemotherapeutic drugs accounts for more than $90 \%$ of cancer specific mortality (7). Based on the characteristics of cancer cell resistance, anticancer drug resistance can be divided into two categories: primary drug 
TABLE 1 | The key characteristics of resistant and nonresistant cancer cells.

\begin{tabular}{ll}
\hline Resistant cells & Nonresistant cells \\
\hline $\begin{array}{l}\text { Cellular level } \\
\text { High GO cell ratio }\end{array}$ & Low G0 cell ratio \\
More proliferative cell & More ready to undergo apoptosis \\
More mesenchymal feature & More epithelial feature \\
Multidirectional differentiation & No differentiation \\
Altered physiology & Physiology maintained \\
Molecular level & \\
Alternative signaling pathway & Stable drug target \\
Activated drug efflux transporter & Inactivated drug efflux transporter \\
DNA repair enhancement & No or little DNA repair \\
High apoptosis threshold & Normal apoptosis threshold \\
Changed drug metabolism & Unchanged drug metabolism \\
Epigenetic change & Homeostatic responses to adversity \\
\hline
\end{tabular}

resistance (PDR) and multidrug resistance (MDR). In PDR, cancer cells may become resistant to one type of anticancer drugs but can still be sensitive to other anticancer drugs of different categories. In the MDR, cancer cells become resistant to the anticancer drugs, with different structures and mechanisms. MDR is the root cause of chemotherapy failure of HCC. Cancers with MDR exhibit several distinctive features as compared with those without. For example, cancers that developed MDR show a high level of apoptotic threshold, aerobic glycolysis, hypoxia, and elevated activity of drug-efflux transporters (8). These features render the tumor cells refractory to chemotherapy. The comparison of characteristics of resistant and non-resistant cancer cells is summarized in Table $\mathbf{1}$.

\section{MICRORNAs MODULATE DRUG RESISTANCE-RELATED MECHANISMS IN HEPATOCELLULAR CARCINOMA}

MicroRNAs (miRNAs) are a series of short non-coding singlestranded RNA molecules encoded by endogenous genes with the molecular length of between 19 and $24 \mathrm{nt}$. They act mainly on the non-coding region at the $3^{\prime}$ end of the messenger RNA to degrade the target RNA or terminate the translation (9). A single miRNA can target several different mRNAs, and a single mRNA can be synergistically inhibited by a number of different miRNAs (10), thereby achieving miRNA-guided posttranscriptional regulation of the gene expression. Numerous studies have consistently proved that the occurrence and progression of HCC are closely related to the differential expression of miRNAs, and a considerable number of miRNAs are directly involved in the drug resistance of cancer cells $(7,11,12)$. According to different regulatory mechanisms, miRNAs can promote or inhibit drug resistance of hepatoma cells. All the researches into the molecules involved in chemotherapy provide a deep understanding of the underlying mechanism of drug resistance. Understanding the mechanisms of how miRNAs are involved in the development of drug resistance can facilitate the development of novel approaches to tackling drug resistance in cancer therapy. Below, we will summarize the data from the latest studies on how HCC develops resistance to chemotherapies (13-17).

\section{Autophagy}

Autophagy is a continuous metabolic process that maintains homeostasis and normal cellular function by degrading and restoring damaged organelles, long-lived, and misfolded proteins in cells (18). The signals that activate the autophagy process usually come from different stress states, such as starvation, hypoxia, oxidative stress, and protein aggregation. The formation of the autophagosome relates to the evolutionarily conserved genes, autophagy-related genes (ATGs), and is usually divided into different stages: initiation, nucleation of the phagophore, formation of autophagosome membrane, fusion with the lysosome, and the degradation of products in vesicles (19). The initiation begins with the activation of the common targets unc-51-like autophagy activating kinase 1 (ULK1) (also known as ATG1) complex $(20,21)$. In the expansion stage, ATG12-ATG5 binds to the ATG16 complex to enlarge the autophagosome membrane and promotes the lipidation of microtubule-associated protein1 light chain3 (MAP1LC3; also known as LC3). In addition, ATG4B binds to ATG7, allowing LC3I and phosphatidylethanolamine (PE) to combine to form LC3II, a lipid-conjugated form of LC3 that commonly considered as a biomarker for autophagosomes (22-24). Ultimately, autophagosomes fuse with lysosomes to form autophagy lysosomes. At present, the role of autophagy in the resistance of HCC remains controversial. Autophagy occurs frequently during tumorigenesis and cancer chemotherapy. Autophagy pathways have been reported to be involved in the development of MDR (23). Thus, anticancer drugs that can directly induce autophagy of MDR cancer cells would be of great therapeutic value. Autophagy can act as a housekeeper to clear damaged organelles or other cellular components and thus protect other cells. Excessive or sustained autophagy has been shown to promote cancer cell death by enhancing the process of apoptotic induction or triggering "autophagic cell death," which is different from type I programmed cell death (apoptosis) (23). Autophagy is closely associated with the formation and progression of cancer and MDR in the clinical settings. Tumors at the advanced stage generally express a higher level of the ATGs (e.g., mTOR, Raptor, Rictor, and LC3) than do the tumors of the early stage, and the expression level of ABCB1(MDR1) in the tumors that developed autophagy is positively correlated with the level of LC3 and Beclin1 (25). On the one hand, autophagy mediates the acquired resistance phenotype of cancer cells during chemotherapy. Hence, inhibition of autophagy can sensitize drug-resistant cancer cells to chemotherapeutic agents. However, autophagy may also induce autophagic cell death. Thus, if applied properly, autophagy can be used to improve the therapeutic effect of MDR cancer, and the role of autophagy in MDR must be elucidated.

In sum, based on the published literatures, autophagy can promote drug resistance in most cases, and miRNAs can make HCC cells resistant or sensitive to anticancer drugs by positive or negative regulating autophagy. 


\section{MicroRNAs Make Hepatocellular Carcinoma Cells Resistant to Drugs by Positive Regulating Autophagy} There is abundant evidence that MDR codevelops with autophagy and miRNAs. The coexistence of autophagy and miRNAs in patients with poor prognosis indicates that both autophagy and miRNA may promote the occurrence of MDR. MiR-185 is an attractant for autophagy. However, when autophagy is inhibited, miR-185 mimics induce more apoptosis (26). It is suggested that miRNAs can positively regulate autophagy and participate in tumor cell resistance. A similar study also has found that overexpression of miR-494 in HCC cells activated by the mTOR pathway increases the resistance of sorafenib (27). Histone deacetylase inhibitors (HDACis) are a group of drugs recommended for the treatment of many solid tumors. Cancer cells resistant to HDACis express high levels of the transcription factor nuclear factor erythroid 2 like-2 (Nrf2), and autophagy has been shown to contribute to Nrf2mediated drug resistance (28). Treatment of cancer cells with HDACi leads to increased Nrf2 expression via upregulation of miR-129-3p. In HDACi-induced autophagy, Nrf2 positively regulates mTOR through miR-129-3p, and HDACi-mediated cell death can be enhanced by inhibiting miRNA-129-3p (28). The role of autophagy in drug resistance is also supported by a recently published study where targeting the PU.1-miR-142-3pATG5/ATG16L1 axis can inhibit the cyto-protective autophagy and overcome sorafenib resistance (29). In the 5-fluorouracil (5-FU; a widely used antineoplastic drug) treated cells, the expression levels of miR-216b and lncRNA MALAT1 are twice as high as those in the control group. Yuan et al. (30) have found that the mechanism may be related to autophagy caused by a high expression of LC3-II and downregulation of p62 in drug-resistant cells, and MALAT1-miR-216b axis modulates MDR of HCC cells by participating in the regulation of autophagy.

\section{MicroRNAs Make Hepatocellular Carcinoma Cells Sensitive to Drugs by Negatively Regulating Autophagy}

Recent studies have reported that autophagy induced by chemotherapeutics may promote resistance of cancer cells to drugs. MiRNAs can induce autophagy negatively in the process of drug resistance. Jin et al. (31) have found that doxorubicin (Dox) could induce autophagy and reduce the level of miR-26a/b in HCC cells. Conversely, when the expression of miR-26a/b maintains at the physiological level, Dox-induced autophagy has been inhibited and increased apoptosis in HCC cells. Furthermore, overexpression of miR-26a/b increases the sensitivity of HCC cells to Dox through negatively regulating ULK1 and promoting apoptosis. MiR-101 can also enhance chemosensitivity of HCC cells and promote drug-induced apoptosis through inhibiting autophagy (32). Involvement of autophagy and miRNAs in the development drug resistance is likely a universal mechanism. For example, cisplatin-based treatment significantly reduces miR-199a-5p expression but activates autophagy (33). On the other hand, overexpression of miR-199a-5p enhances the inhibitory effect of cisplatin on cell proliferation. Similarly, blockage of autophagy also inhibits cell proliferation induced by downregulation of miR$199 a-5 p$, suggesting that miR-199a-5p regulates chemoresistance through autophagy.

In addition to acting on autophagy individually, miRNAs can also bind to other carrier substances and inhibit other key molecules of autophagy to enhance drug sensitivity. For example, autophagy has been proved to promote sorafenib resistance, and miR-375 has been indicated to inhibit autophagy (34). Further research has found that miR-375/Sf-LCC NP can transport sorafenib and miR-375 into HCC cells and tumor tissues, thereby increasing the retention time of sorafenib, inhibiting autophagy, and producing enhanced anti-tumor effects (35). A study reported by Gao et al. (36) indicated that a dietary flavonoid apigenin significantly enhances Dox sensitivity and miR-520b expression in HCC. Furthermore, miR-520b can inhibit ATG7, an important autophagy-dependent molecule, indicating that the miR-520b/ATG7 axis has a positive effect on the chemosensitivity of HCC.

Figure 1 and Table 2 summarize the role of miRNAs in the regulation of autophagy-mediated drug resistance.

However, miRNAs can also inhibit autophagy through interacting with other pathways to achieve drug resistance. MiR21 is proved to be upregulated in sorafenib-resistant HCC cells (38). Moreover, miR-21 was shown to inhibit the expression of phosphatase and tensin homolog deleted on chromosome 10 (PTEN) and to activate AKT pathways (39). He et al. have found that the activated AKT/PTEN pathway in sorafenib-resistant HCC cells exerts a positive effect on sorafenib resistance (40). The resistance to sorafenib can be restored when the HCC cells are treated with miR-21 mimics, and this effect is likely mediated through inhibiting autophagy via the AKT/PTEN pathway. Tumor metastasis is one of the adverse outcomes in patients with chemoresistance. MiR-30a is previously reported to be associated with vascular invasion, metastatic potential, and HCC recurrence (37). Fu et al. have reported that downregulation of miR-30a mediates Beclin1 and ATG5-dependent autophagy in metastatic HCC, resulting in "anoikis resistance," which is considered to be the first step in metastasis of HCC cells (41).

\section{Membrane Transporter}

MDR in HCC cells is mainly associated with two classical families of membrane transporters: (1) ATP-binding cassette (ABC) transporter superfamily, including P-glycoprotein (P-gp; also known as MDR1/ABCB1), MDR-associated protein $1(\mathrm{MRP} 1) / \mathrm{ABCCl}$, and breast cancer resistance protein (BCRP)/ABCG2. These transporters function as energydependent transmembrane drug delivery pumps and can pump intracellular substances, including a variety of anticancer drugs, out of cancer cells, leading to chemoresistance and chemotherapy failure; (2) solute carrier (SLC) transporter superfamily. Transporters in this category can disrupt the absorption of anticancer drugs in cells. Overexpression of these two types of transporters can induce drug resistance in cancer cells, but the $\mathrm{ABC}$-transporter proteins are the main cause of drug resistance in hepatoma cells (42-44). 


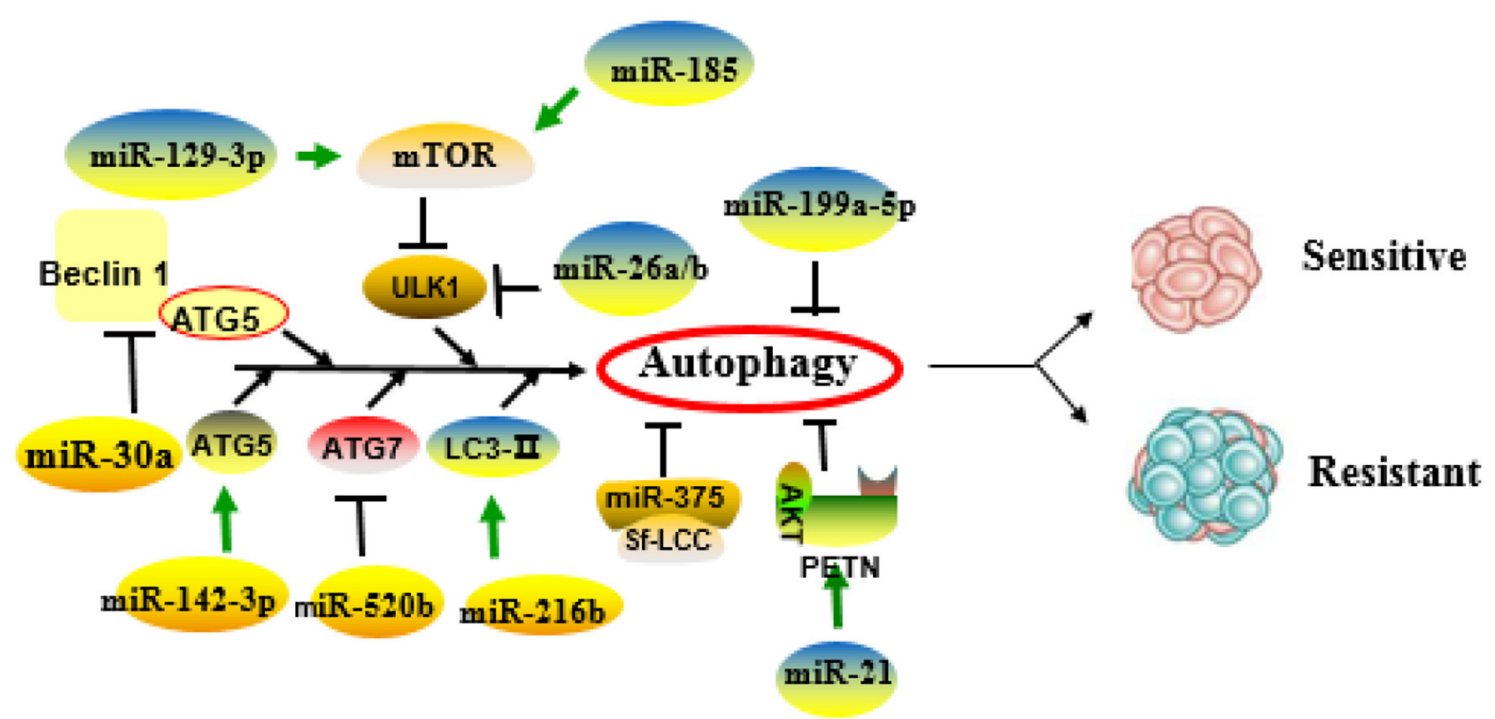

FIGURE 1 | Role of microRNAs (miRNAs) in the regulation of autophagy-related drug resistance. MiRNAs exert important roles in drug resistance through positive or negative regulation of key molecules or pathways of autophagy.

TABLE 2 | MiRNAs known to modulate chemoresistance through regulating autophagy.

\begin{tabular}{|c|c|c|c|c|c|}
\hline MiRNA & Target & MiRNA regulated autophagy & Autophagy regulated resistance & Drug & Reference \\
\hline MiR-185 & & Positively & Positively & & (26) \\
\hline MiR-494 & mTOR & Positively & Positively & Sorafenib & (27) \\
\hline MiR-142-3p & ATG5/ATG16L1 & Positively & Positively & Sorafenib & (29) \\
\hline MiR-26b & LC3-II, P62 & Positively & Positively & $5-\mathrm{FU}$ & (30) \\
\hline MiR-199a-5p & & Negatively & Positively & Cisplatin & (33) \\
\hline MiR-375 & & Negatively & Positively & Sorafenib & (35) \\
\hline MiR-520b & ATG7 & Negatively & Positively & Doxorubicin & (36) \\
\hline MiR-30a & Beclin1, ATG5 & Negatively & Positively & Sorafenib & (37) \\
\hline
\end{tabular}

miRNAs, microRNAs; HDACis, histone deacetylase inhibitors; 5-FU, 5-fluorouracil.

\section{P-glycoprotein/MDR1/ABCB1}

$\mathrm{P}$-gp is a transmembrane glycoprotein encoded by MDR gene MDR1 with a molecular weight of $\sim 170 \mathrm{kDa}$. It exhibits a high expression on multidrug-resistant cell membranes and can pump out anticancer drugs (45), resulting in the decrease in intracellular drug concentration, reduced drug cytotoxicity, and ultimately drug resistance. In addition, P-gp has recently been shown that it may confer resistance to chemotherapy-induced apoptosis (46). P-gp has a very broad spectrum of substrates that can export various drugs out of cells (47). The high level of P-gp in drug-resistant cells may be due to two mechanisms: a high basal level of P-gp in cancer tissue and chemotherapyinduced high expression in cancer cells (48). Previous studies have reported that the expression of miRNAs in drug-resistant cells of various tissues and organs was negatively associated with the expression of $\mathrm{ABCB} 1(49,50)$, suggesting that the expression of some miRNAs in HCC was likely related to the alterations of MDR-1/P-gp expression and change of MDR phenotype. To support this notion, high expression of miR-122 in HCC cells resulted in a decrease in the expression of MDR-related genes, including P-gp (48). In another study, Yang et al. (51) have found that overexpression of miR-223 enhanced the sensitivity of HCC cells to anticancer drugs, whereas overexpression or silencing $\mathrm{ABCB} 1$ in these cells could rescue the response to anticancer drugs. Another miRNA is miR-27a, which has been reported to promote the occurrence and differentiation of various tumors (52). Moreover, miR-27a can also act as a chemotherapeutic drug resistance gene in multiple cancers including ovarian cancer, leukemia, pancreatic cancer, and adenocarcinoma. Chen et al. (53) have demonstrated that overexpression of miR-27a in the BEL/5-FU cells (multidrug-resistant cell line of liver cancer) reduced the expressions of MDR1/P-gp and $\beta$-catenin 
but enhanced the sensitivity of these cells to 5-FU-induced apoptosis, suggesting that miR-27a may be a new therapeutic target for HCC.

\section{MRP/ABCC}

MRP, also known as ABCC, mediates the efflux of potentially harmful substances in cells. Among them, $\mathrm{ABCC} 1, \mathrm{ABCC}$, and $\mathrm{ABCC} 3$ can participate in the MDR of malignant tumors, but their ability to induce drug resistance is lower than that of $\mathrm{ABCB} 1 . \mathrm{ABCC} 1$ and $\mathrm{ABCC} 2$ cannot transport unmodified foreign substances (54). Exogenous substances must first bind to glutathione (GSH) under the action of glutathione thiotransferase (GST) and then be transported out of the cells through $\mathrm{ABCCl}$ and $\mathrm{ABCC} 2(55,56)$. At present, there are few reports on miRNA regulation of MRP against the uptake and translocation of anticancer drugs. A study reported by $\mathrm{Ma}$ et al. (57) have shown that ABCCI $3{ }^{\prime}$-untranslated region (3'UTR) has binding sites for miR-133a and miR-326. Both miR133a and miR-326 can reduce the expression of $\mathrm{ABCCl}$ in the hepatoma cell line HepG2 and enhance the sensitivity of the cells to Dox, suggesting that miR-133a and miR-326 mediate MDR through modulating ABCC1. However, as MRP mRNA may have a different secondary structure, the miRNAs may produce different biological functions when they act on different MRPs. For example, miR-379 downregulates ABCC2 in a haplotypedependent manner, in that $\mathrm{ABCC} 2$ can be slightly inhibited when the haplotypes are wild type, whereas $\mathrm{ABCC} 2$ can be more strongly inhibited when the haplotypes are mutant (58).

MiRNAs Involved in Membrane Transporter-Mediated Resistance Are Summarized as Figure 2.

\section{Epithelial-Mesenchymal Transition}

Epithelial-mesenchymal transition (EMT) is the process of transforming closely connected and immobile epithelial cells into loosely connected and migrating stromal tissue (59). The reversal process is called mesenchymal-epithelial transition (MET). In order to achieve phenotypic transformation, cells need to reprogram their gene expression (60). Reprogramming of EMTrelated gene sequences means that E-cadherin downregulation leads to the separation of cell junctions, thereby promoting the transformation of epithelial phenotype to mesenchymal phenotype and the alteration of genes that encode cytoskeleton (61). Currently, three well-established groups of transcriptional regulators have been identified as important factors regulating the expression of EMT markers, including snail zinc finger protein family (Snail1 and Snail2); zinc finger E-box binding family (Zeb1 and Zeb2); and basic helix-loop-helix family (Twist1, Twist2, E12, E47, and differentiation inhibitory proteins). These transcription factors can independently or synergistically inhibit the expression of epithelial genes and activate interstitial genes, thereby regulating the $\operatorname{EMT}(62,63)$.

By undergoing EMT, cancer cells can acquire resistance to chemotherapies (15). The relationship between EMT and drug resistance was first discovered in 2008 and was further verified by the findings that blocking or reversing EMT could convert the resistant cells into sensitive cells (64). In addition, the role of EMT in drug resistance has been demonstrated by the

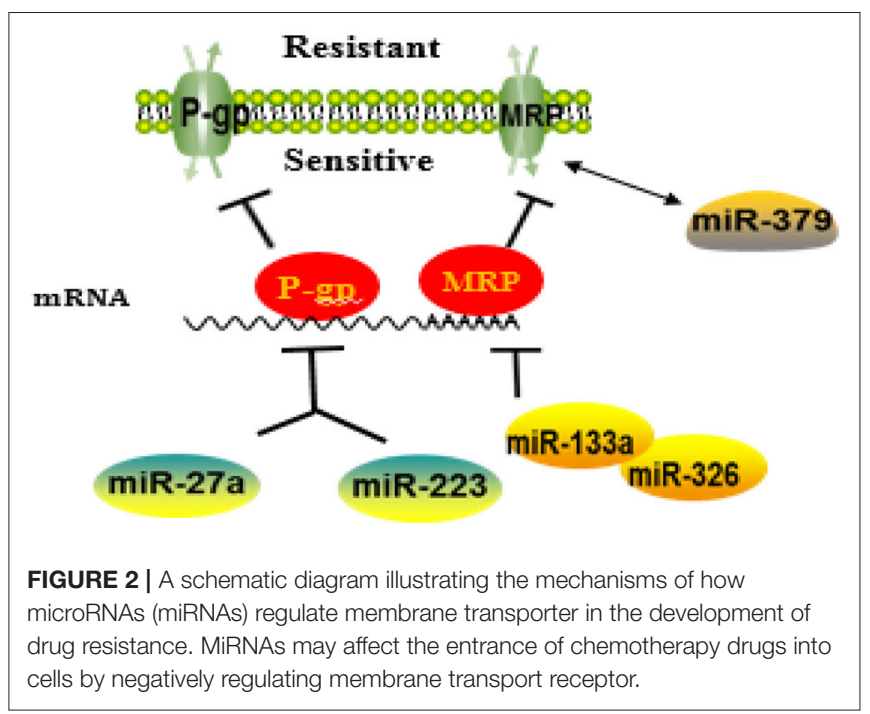

studies showing that anticancer therapies could render the cancer cells to acquire cancer stem cell (CSC) characteristics through EMT (65). It is now known that many signaling pathways, including TGF- $\beta$, AKT, ERK, Notch, and Wnt signaling, affect the chemoresistance of HCC cells by participating in the EMT process $(66,67)$. Recently, multiple miRNAs have been indicated to play key roles in the key regulation of EMTrelated cancer resistance. For example, resistance against antiEGFR therapies (e.g., cetuximab, gefitinib, and erlotinib) has been demonstrated to be closely related to the acquisition of EMT phenotypes via loss of miR-200c in a variety of cancer types (68). MiRNA-200 family (including miR-200a, miR-200b, miR-200c, miR-141, and miR-429) directly target and regulate the expression of the E-cadherin transcriptional repressors Zeb1 and Zeb2 in multiple cancers, and the inhibition of miR-200c increases E-cadherin expression and induces EMT (69). Another miRNA miR-130a-3p has been reported to regulate gemcitabine resistance. It has found that miR-130a-3p could target Smad4 and that overexpression of miR-130a-3p or downregulation of Smad4 could inhibit cell detachment, adhesion, migration, and invasion of gemcitabine-resistant HCC (GR-HCC) cells (70). Platelet-derived growth factor-D (PDGF-D), a critical regulator for EMT, has been reported to regulate gemcitabine resistance (71). PDGF-D is highly expressed in GR-HCC cells and can significantly inhibit miR-106a expression and subsequently promote Twist1 overexpression in vitro. Finally, the miRNA miR-122 has been reported to play an important role in HCC drug resistance through regulating EMT. It has been shown that overexpression of miR-122 could significantly inhibit EMT through repressing the level of Zeb1/2, Snail1/2, N-cadherin, and vimentin but upregulating E-cadherin expression. On the other hand, downregulation of miR-122 induces the opposite effect (72). Xia et al. have demonstrated that miR-153 inhibited Snail by directly targeting its $3^{\prime}$-UTR (73). In addition, studies on miRNAs have shown that miRNAs responded to the regulation of tumor EMT pathway genes. MiR-195 has been proven to inhibit Smad7 


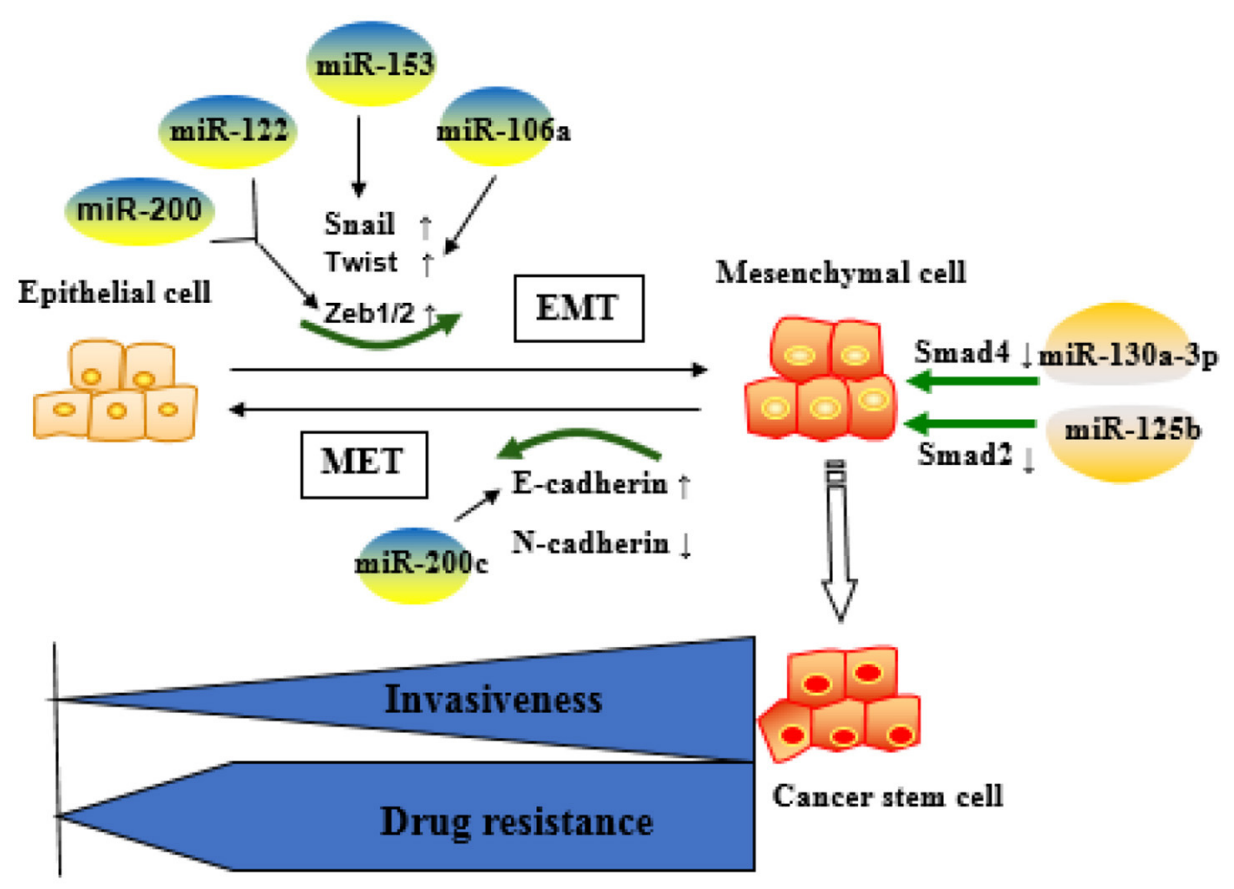

FIGURE 3 | Role of microRNAs (miRNA)-regulated epithelial-mesenchymal transition (EMT) in the development of resistance. Epithelial cells are more sensitive to chemotherapeutic drugs, whereas mesenchymal cells are resistant to the drugs and more aggressive. MiRNAs mainly affect drug resistance through negative regulation of key molecules in the EMT process.

expression by binding to its $3^{\prime}$-UTR, thereby enhancing TGF$\beta$-Smad signaling (74). MiR-122 represses MDR1 expression via targeting the Wnt/ $\beta$-catenin pathway directly, strengthening the sensitivity of HCC to oxaliplatin (75). Immunotherapy stimulates the body's specific immune response by enhancing the selfregulating ability of the immune system and playing a positive role in improving the prognosis. Zeb1 is reported to relieve miR200 repression of $\mathrm{PD}-\mathrm{L} 1$ on cancer cells, leading to $\mathrm{CD} 8^{+} \mathrm{T}$-cell immunosuppression and metastasis (76).

These reports indicate that the miRNAs are key factors in determining the fate of drug-resistant cancer cells by regulating EMT. Commonly identified miRNAs involved in EMT-mediated resistance are summarized as Figure 3.

\section{Tumor Microenvironment}

The hepatic tumor microenvironment is a special environment for tumor cell growth formed by the interaction between tumor cells and extracellular matrix (ECM) (77). The main components of tumor microenvironment include (a) cellular components, such as angiogenic cells, immune cells, tumorassociated fibroblasts, endothelial cells, and adipocytes; (b) physical components in the ECMs; and (c) biochemical components, including cytokines, adhesion molecules, and oxygen tension $(78,79)$. Drug resistance occurs not only in cancer cells but also in the microenvironment where cancer cells reside. The microenvironment-mediated MDR is a result of continuous crosstalk between the cancer cells and their surrounding stroma. Soluble factors secreted by tumor cells or stromal cells can induce microenvironment-mediated drug resistance and subsequently favor tumor progression (80). Adhesion of tumor cells to stromal fibroblasts or to ECM components can also blunt therapeutic response $(77,78)$.

\section{Cancer Stem Cells}

CSCs are defined as a small proportion of cancer cells with strong self-renewal capacity and multidirectional differentiation potential (81). Most CSCs are in the G0 phase of cell cycle and are resistant to chemotherapy and radiotherapy, leading to tumor relapse and treatment failure $(82,83)$. Conventional therapies often fail because they do not completely eradicate CSCs, as this subset of cells often evades the treatment via therapy-induced EMT. Importantly, non-CSCs can spontaneously undergo EMTlike changes in response to chemotherapy and acquire CSC-like features, thereby leading to drug resistance (65).

CSCs have been identified in many types of cancers, such as liver cancer, colorectal cancer, pancreatic cancer, lung cancer, and breast cancer (84). Liver cancer stem cells (LCSCs) are now considered the source cells for the initiation, progression, and recurrence of liver cancer $(85,86)$. Recent studies have shown that that a variety of miRNAs can regulate the MDR of LCSCs through interacting with key molecular pathways such as Wnt/ $\beta$ catenin, TGF- $\beta$, and JAK/STAT signaling (86). For example, Let-7 miRNAs, especially let-7a, can eliminate LCSCs via inhibiting Wnt signaling pathway, thereby significantly improving the sensitivity to chemotherapeutic agents (87). Tumor necrosis factor (TNF)-associated apoptosis-inducing ligand (TRAIL) is 
considered as a promising anticancer molecule, as it can selectively induce apoptosis in cancer cells without damaging normal cells. MiR-25 is significantly upregulated in LCSCs as compared with the non-CSCs, and the resistance of CSC to TRAIL appears to be mediated by miR-25, because knockdown of miR-25 significantly increases the sensitivity of LCSCs to TRAILinduced apoptosis via PTEN/PI3K/AKT/Bad signaling pathway (88). Furthermore, downregulated miR-148b maintains CSC properties by targeting NRP1 in HCC (89). In another example, miR-125b has been found to be negatively correlated with EMT phenotype and CSC marker expression in HCC specimens, and consequently, overexpression of miR-125b could attenuate the EMT phenotype in HCC cancer cells by targeting Smad2 and Smad4 (90).

\section{Hypoxia and the Warburg Effect}

Rapid tumor growth increases the diffusion distance and oxygen consumption. Meanwhile, abnormal proliferation of tumor vasculatures and collapse of the blood vessel wall may impair the balance between the oxygen supply and demand of tumor cells, leading to relative hypoxia in the tumor environment. The survival of tumor cells in the hypoxic regions and the progression of solid tumors are regulated by hypoxia-inducible factor (HIF) (91). HIF is a heterodimer composed of an $\alpha$ subunit and a $\beta$ subunit, mainly containing HIF- $1 \alpha$, HIF- $2 \alpha$, and HIF- $\beta$ (92). It is known that HIF can interact with miRNAs in the regulation of drug resistance (93). For example, miR-338-3p has been found to enhance the sensitivity of HCC cells to sorafenib and promote HCC apoptosis by downregulating HIF-1 $\alpha$ (94). HIF-1a can also achieve drug resistance by maintaining the characteristics of CSC. MiR-16 has been shown to reverse sorafenib resistance in HCC cells through targeting 14-3-3eta $3^{\prime}$-UTR and inhibiting 14-33 eta/HIF-1 $\alpha /$ CSC (95). Similar studies have been reported on the correlation between lncRNA MALAT1 and HIF $\alpha$ subunits, in HCC cells, confirming at least two miR-216b binding sites in IncRNA MALAT1, suggesting a possible role of HIF- $2 \alpha-$ MALAT1-miR-216b axis in the regulation of MDR in HCC (30). During immunotherapy, hypoxia-induced miR-210 can significantly reduce the sensitivity of tumor cells to cytotoxic T lymphocyte (CTL)-mediated lysis via targeting PTPN1, HOXA1, and TP53I11 (96).

Normal cells are often energized by the aerobic oxidation of sugar in the presence of sufficient oxygen and by the glycolysis pathway in the anoxic environment. However, most cancer cells do not obtain energy through mitochondrial oxidative phosphorylation even in the presence of sufficient oxygen, but instead, they use the aerobic glycolysis, a phenomenon defined as the Warburg effect (97). The Warburg effect converts glucose into lactic acid to produce ATP, and the accumulation of lactic acid in the extracellular environment will

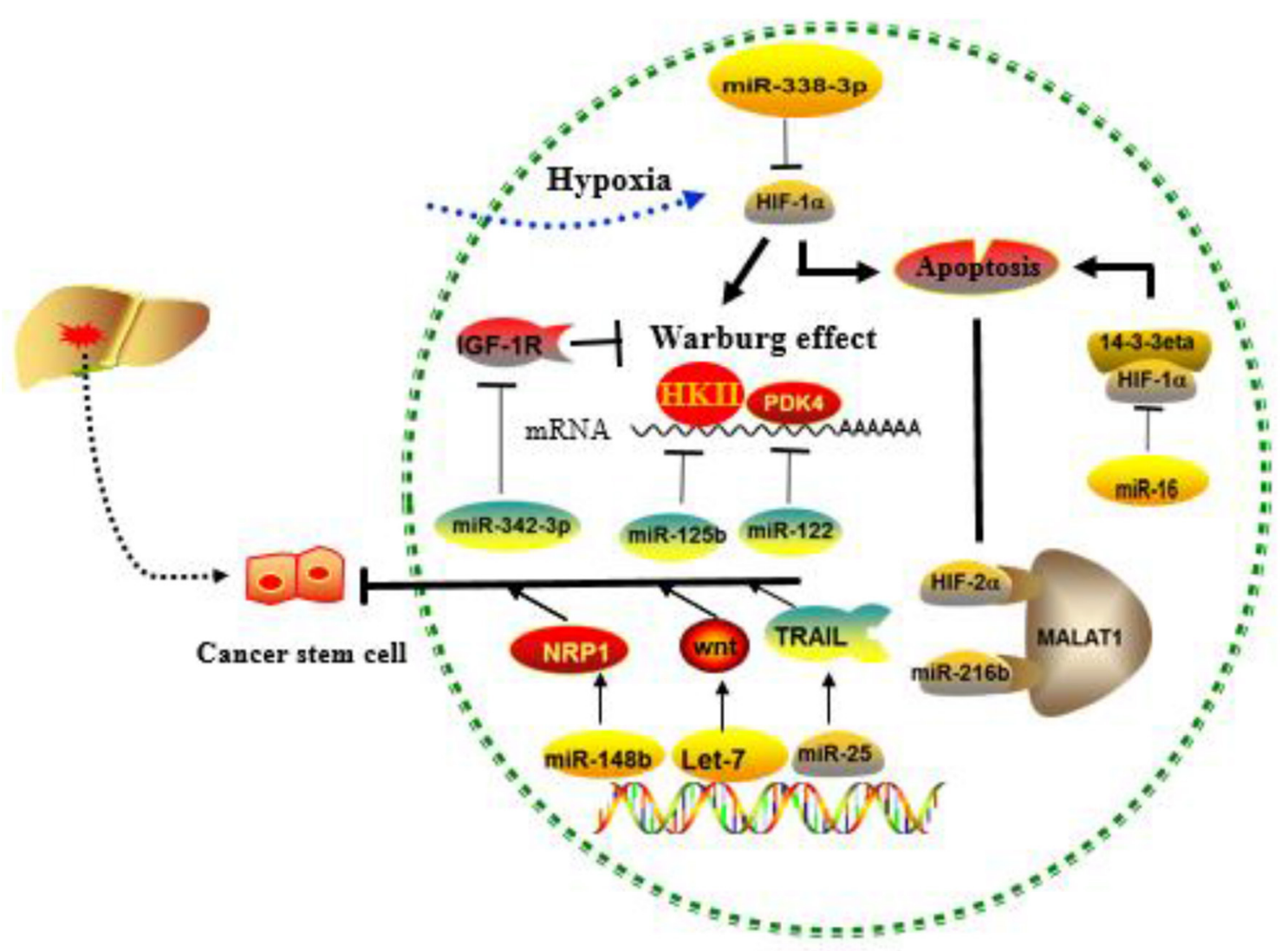

FIGURE 4 | Role of cancer stem cells (CSCs), hypoxia, and the Warburg effect regulated by MICRORNAS (miRNAs) in the development of drug resistance. MiRNAs mainly affect drug resistance through negative regulation of key molecules in the above process. 
gradually increase, representing the transformation of oxidative phosphorylation to glycolysis. Indeed, increased consumption of glucose by cancer cells in order to produce energy is considered a major biochemical feature of the cancer cells (98). The intrinsic mechanism of the Warburg effect is mainly focused on the abnormalities of oncogenes and tumor suppressor genes, as well as related enzymes in sugar metabolism (99101). miRNA-129-5p and miR-342-3p have been reported to affect HCC progression by blocking the Warburg effect (102, 103). MiR-125b, a tumor suppressor in HCC cells, downregulated in resistance of $\mathrm{HCC}$ cells to 5-FU, is likely mediated by miR-125b, a tumor suppressor in HCC cells that inhibit the target hexokinase II (HK II) related to glucose metabolism (104). Studies have also found that extracellular glucose and lactic acid are environmental factors for maintaining the characteristics in CSCs. Surprisingly, liver-specific miR122 is down-expressed in $\mathrm{CD}_{133^{+}}{ }^{+}$CSCs. When miR-122 is upregulated, PDK4 can be targeted to inhibit CSCs, which provides another solution for chemoresistance (105). MiR342-3p inhibits IGF-1R-mediated PI3K/AKT/GLUT1 signaling pathway by reducing glucose uptake, lactate production, ATP production, and extracellular acidification rate (ECAR) and increasing oxygen consumption rate (OCR) of hepatoma cells to achieve the inhibition of cell proliferation (102). MiRNAs involved in tumor microenvironment-mediated resistance are summarized in Figure 4.

\section{Genes and Proteins That Regulate Apoptosis}

The intrinsic or acquired resistance to apoptosis is one of the hallmarks of human cancers. Defects in apoptosis are the basis of drug resistance, and chemotherapy often fails (106). Aberrant expression or mutation of genes encoding crucial apoptotic

TABLE 3 | MiRNAs that modulate drug chemoresistance through intracellular mechanisms.

\begin{tabular}{|c|c|c|c|c|c|}
\hline MiRNA & Target & Mechanism & MiRNA regulated mechanism & Drug & References \\
\hline MiR-223 & ABCB1 & Membrane transporter & Negatively & Doxorubicin & (51) \\
\hline MiR-27a & MDR1, $\beta$-catenin & Membrane transporter & Negatively & $5-F U$ & $(52)$ \\
\hline MiR-133/326 & $\mathrm{ABCC} 1$ & Membrane transporter & Negatively & Doxorubicin & $(57)$ \\
\hline MiR-379 & ABCC2 & Membrane transporter & Negatively & & $(58)$ \\
\hline MiR-338-3p & $\mathrm{HIF}-1 \alpha$ & Hypoxia & Negatively & Sorafenib & (94) \\
\hline MiR-125b & HK II & Warburg effect & Negatively & $5-F U$ & $(104)$ \\
\hline MiR-122 & PDK4 & CSC, Warburg effect & Negatively & & $(105)$ \\
\hline MiR-342-3p & IGF-1R & Warburg effect & Negatively & & $(102)$ \\
\hline MiR-539 & Bcl-2, Bcl-xL, Stat3 & Apoptosis & Negatively & & $(110)$ \\
\hline MiR-34a & $\mathrm{Bcl}-2$ & Apoptosis & Negatively & Sorafenib & $(111)$ \\
\hline MiR-363 & Mcl-1 & Apoptosis & Negatively & Cisplatin & $(112)$ \\
\hline MiR-25 & PTEN/PI3K/AKT/Bad & CSC, apoptosis & Negatively & TRAIL & (88) \\
\hline MiR-19a-3p & PTEN/AKT & Apoptosis & Negatively & Sorafenib & $(118)$ \\
\hline MiR-216a/217 & PTEN, Smad7 & Apoptosis & Negatively & Sorafenib & $(119)$ \\
\hline MiR-205-5p & PTEN/JNK/ANXA3 & Apoptosis & Negatively & $5-F U$ & $(120)$ \\
\hline MiR-760 & Notch1 & Apoptosis & Negatively & Doxorubicin & $(121)$ \\
\hline MiR-622 & KRAS & Apoptosis & Negatively & Sorafenib & $(124)$ \\
\hline Let-7g & KRAS & Apoptosis & Negatively & & $(125)$ \\
\hline
\end{tabular}

miRNAs, microRNAs; 5-FU, 5-fluorouracil; CSC, cancer stem cell; PTEN, phosphatase and tensin homolog deleted on chromosome 10.

TABLE 4 | MiRNAs that modulate drug chemoresistance through extracellular mechanisms.

\begin{tabular}{|c|c|c|c|c|c|}
\hline MiRNA & Target & Mechanism & MiRNA regulated mechanism & Drug & References \\
\hline MiR-200c & E-cadherin, Zeb1/2 & EMT & Negatively & Anti-EGFR & (69) \\
\hline MiR-130a-3p & Smad4 & EMT & Negatively & Gemcitabine & $(70)$ \\
\hline MiR-106a & PDGF-D, Twist1 & EMT & Negatively & Gemcitabine & $(71)$ \\
\hline MiR-122 & Zeb1/2, Snail1/2 & EMT & Negatively & & $(72)$ \\
\hline MiR-153 & Snail & EMT & Negatively & & $(73)$ \\
\hline Let-7a & Wnt & CSC & Negatively & & (87) \\
\hline MiR-25 & PTEN/PI3K/AKT/Bad & CSC, apoptosis & Negatively & TRAIL & (88) \\
\hline MiR-148b & NRP1 & CSC & Negatively & & (89) \\
\hline MiR-125b & Smad2/4 & CSC, EMT & Negatively & & (90) \\
\hline
\end{tabular}

EMT, epithelial-mesenchymal transition; CSC, cancer stem cell; PTEN, phosphatase and tensin homolog deleted on chromosome 10. 
proteins can induce cancer cells to have both the intrinsic survival advantage and inherent resistance to chemotherapeutic drugs. A large variety of genes regulating apoptosis have been discovered, such as the Bcl-2 family and tumor suppressor p53, p63/p73, PTEN, KRAS, and BRAF.

\section{B-Cell Leukemia-2}

Bcl-2 family is currently the most valuable gene family that regulates mitochondrial apoptosis. According to the different effects of Bcl-2 family on apoptosis, the Bcl-2 family genes can be divided into anti-apoptotic and pro-apoptotic. The antiapoptotic genes include $\mathrm{Bcl}-2, \mathrm{Bcl}-1, \mathrm{Mcl}-1$, Bag-4, Boo/Diva, and $\mathrm{Bcl}-\mathrm{w}$, whereas the pro-apoptotic genes include $\mathrm{Bcl}-\mathrm{xs}, \mathrm{Bax}$, Bad, Bak, Hrk, and Bim $(107,108)$. The Bcl-2 family genes interact to determine cell fate. In the current review, we mainly focus on miRNAs involved in the anti-apoptotic signaling and drug resistance.

$\mathrm{Bcl}-2$ is the most studied gene associated with anticancer drug resistance (109). It is confirmed that arsenic trioxide-induced apoptosis in HCC cells could be enhanced by overexpression of miR-539, and this has demonstrated to be mediated by decreased expression of Bcl-2, Bcl-xL, and phosphorylation of Stat3 (110). Overexpression of miR-34a has been shown to inhibit Bcl-2 and, therefore, promote sorafenib-induced apoptosis and toxicity in HCC cells (111). In another study, significantly reduced level of
miR-363 has been found in cisplatin-resistant HepG2 (HepG2 $\mathrm{R})$ cells as compared with the naïve HepG2 cells, but exogenous miR-363 remarkably has overcame cisplatin resistance in HepG2$\mathrm{R}$ cells. Mechanistic studies have demonstrated that miR-363 directly targets Mcl-1 3'-UTRs, leading to decrease cisplatin resistance (112). LCSCs are regarded as the critical subset in the pathogenesis of HCC and therapy resistance. In addition, the activation of pro-survival pathways such as PI3K-AKT has been shown to promote drug resistance. Feng et al. have reported that the increased level of miR-25 is associated with the sensitivity of LCSCs to TRAIL-induced apoptosis (88). As such, knockdown of miR-25 may represent a potential strategy for increasing TRAIL by an induced killing effect targeting the PTEN/PI3K/AKT/Bad signaling pathway.

\section{Phosphatase and Tensin Homolog Deleted on Chromosome 10}

PTEN is a tumor suppressor gene that is essential for maintaining normal cell survival $(113,114)$ and is frequently mutated or deleted in several human cancers including HCC (115). Deletion of the PTEN gene or inactivation of a single PTEN allele can promote cancer development through negatively regulating AKT signaling (115). Hence, loss of PTEN leads to unrestricted proliferation of cancer cells and the loss of sensitivity of cancer cells to chemotherapeutic drugs $(116,117)$.

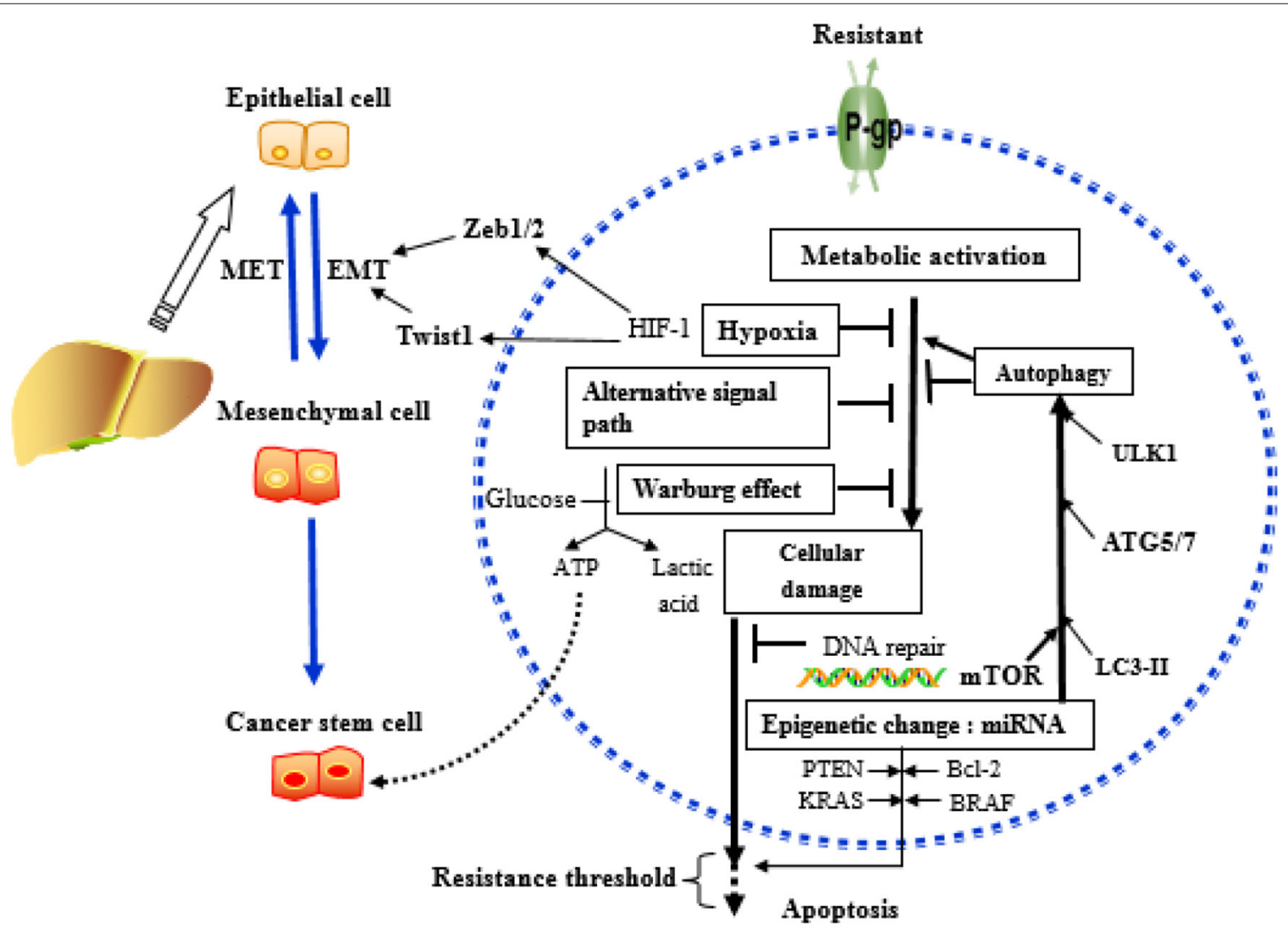

FIGURE 5 | Key mechanisms related to drug resistance in hepatoma cells. MicroRNAs (miRNAs) can affect the outcome of chemotherapy, mainly acting on key molecules or signaling pathways related to the above mechanisms. 
Recent studies have reported that miRNAs can regulate sorafenib resistance via interacting with the PTEN/AKT pathway (118). For example, it has recently been reported that miR19a-3p induced sorafenib resistance by inhibiting PTEN and subsequent activation of PI3K/AKT, leading to increased EMT, cell migration, and acquisition of stem cell-like properties in HCC cells, rendering these cells more resistant to sorafenib (119). Similarly, inhibition of miR-205-5p can reverse the resistance of HCC cells to 5-Fu via activation of PTEN/JNK/ANXA3 axis (120). On the other hand, miR-760 has been reported to overcome resistance of HCC cells to Dox through activating PTEN-dependent PI3K/AKT signaling and targeting Notch1 pathway (121). These studies suggest that the mechanisms may differ among different drugs and cellular context.

\section{Others}

An important molecular switch that regulates proliferation, differentiation, and apoptosis is through activating MAPK and PI3K/AKT signaling pathways. The RAS family consists of KRAS, NRAS, and HRAS; among them, KRAS mutation is one of the most common molecular events, seen in $17-25 \%$ of human cancers (122). Tyrosine kinase inhibitors (TKIs) are representative drugs that function through blocking RAS pathways; hence, KRAS mutation is a mechanism leading to TKI resistance (123). Published studies have shown that miRNA622 can inhibit KRAS signaling, leading to resensitization of sorafenib-resistant cells (124). Let-7g is reported to regulate EMT by downregulating the re-expressed KRAS (125). BRAF protein and KRAS are both upstream regulators in the RAS-RAF-MEKERK signaling pathway. In patients with advanced HCC, those with BRAF mutation are more aggressive and resistant to TKI (126). Another miRNA, miR-550a-3-5p, has also reported to reverse the resistance of HCC cells to BRAF inhibitors through direct targeting of YAP (127).

The miRNAs reported to modulate chemoresistance through intracellular mechanisms are summarized as Table 3. The miRNAs reported to modulate chemoresistance through extracellular mechanisms are summarized in Table 4.

Figure 5 summarizes the key mechanisms involved in the development of drug resistance in HCC.

\section{CONCLUSIONS}

Drug resistance is a major problem in cancer therapy. Understanding how drug resistance occurs and how it is

\section{REFERENCES}

1. Yi P-S, Wang H, Li J-S. Evolution and current status of the subclassification of intermediate hepatocellular carcinoma. World J Gastrointest Surg. (2020) 12:85-92. doi: 10.4240/wjgs.v12.i3.85

2. Siegel RL, Miller KD, Jemal A. Cancer statistics, 2019. CA Cancer J Clin. (2019) 69:7-34. doi: 10.3322/caac.21551

3. Bray F, Ferlay J, Soerjomataram I, Siegel RL, Torre LA, Jemal A. Global cancer statistics 2018: GLOBOCAN estimates of incidence and mortality worldwide for 36 cancers in 185 countries. CA Cancer J Clin. (2018) 68:394-424. doi: $10.3322 /$ caac. 21492 regulated at the molecular level is a prerequisite for developing effective treatment approaches for liver cancer. At present, drug resistance is believed to be multifactorial involving abnormalities in autophagy, apoptosis, membrane transporters, EMT, and tumor microenvironment. The functions of drug resistance genes, the activation mechanism, and the regulation of miRNAs have been extensively studied. In this review, we present potential molecular, cellular, and microenvironmental mechanisms to understand drug resistance in HCC systematically and comprehensively. Autophagy can not only act as a housekeeper but also promote tumor cell death by enhancing the process of inducing apoptosis, playing a two-way regulation in the drug resistance process. P-gp and MRP are important components of the membrane transporter, which have a mediating effect on the entry and exit of chemotherapeutic drugs into tumor cells. EMT and MET, together with the critical signaling pathway, exist in the two transition processes, exerting a critical role in mediating tumor metastasis drug resistance. In addition, the biological processes involved in tumor microenvironment, such as CSCs, hypoxia, and the Warburg effect, function as an essential part in tumor progression, in which all miRNAs are involved in drug resistance. Likewise, Bcl-2, PTEN, KRAS, and BRAF are the genes that regulate apoptosis, acting as an important signaling molecule of their downstream pathway involved in the formation of tumor resistance. The resistance to tumors may be the result of synergistic and mediating effects of multiple genes and multiple mechanisms, but the detailed mechanism of MDR formation in tumor cells has not yet been fully elucidated. The review provides critical information on how miRNAs regulate the development of drug resistance in HCC and will shed light on the development of novel approaches for tackling drug resistance in liver cancer management.

\section{AUTHOR CONTRIBUTIONS}

FX selected the topic and directed writing. LQ reviewed it. YL wrote manuscript. QL collected information. All authors contributed to the article and approved the submitted version.

\section{FUNDING}

This work was financially supported by the National Natural Science Foundation of China (no. 81773478).
4. Miller KD, Nogueira L, Mariotto AB, Rowland JH, Yabroff KR, Alfano CM, et al. Cancer treatment and survivorship statistics, 2019. CA Cancer J Clin. (2019) 69:363-85. doi: 10.3322/caac.21565

5. Rodriguez-Hernandez MA, de la Cruz-Ojeda P, Gallego P, Navarro-Villaran E, Stankova P, Del Campo JA, et al. Dose-dependent regulation of mitochondrial function and cell death pathway by sorafenib in liver cancer cells. Biochem Pharmacol. (2020) 176:113902. doi: 10.1016/j.bcp.2020.1 13902

6. Bedard PL, Hyman DM, Davids MS, Siu LL. Small molecules, big impact: 20 years of targeted therapy in oncology. Lancet. (2020) 395:1078-88. doi: 10.1016/S0140-6736(20)30164-1 
7. Si W, Shen J, Zheng H, Fan W. The role and mechanisms of action of microRNAs in cancer drug resistance. Clin Epigenet. (2019) 11:25. doi: 10.1186/s13148-018-0587-8

8. Lee WK, Kolesnick RN. Sphingolipid abnormalities in cancer multidrug resistance: Chicken or egg? Cell Signal. (2017) 38:134-45. doi: 10.1016/j.cellsig.2017.06.017

9. Pea A, Jamieson NB, Braconi C. Biology and clinical application of regulatory RNAs in hepatocellular carcinoma. Hepatology. (2020). doi: 10.1002/hep.31225. [Epub ahead of print].

10. Yao Q, Chen Y, Zhou X. The roles of microRNAs in epigenetic regulation. Curr Opin Chem Biol. (2019) 51:11-7. doi: 10.1016/j.cbpa.2019.01.024

11. Lai Y, Feng B, Abudoureyimu M, Zhi Y, Zhou H, Wang T, et al. Noncoding RNAs: emerging regulators of sorafenib resistance in hepatocellular carcinoma. Front Oncol. (2019) 9:1156. doi: 10.3389/fonc.2019.01156

12. Tricoli L, Niture S, Chimeh U, Kumar D. Role of microRNAs in the development of hepatocellular carcinoma and acquired drug resistance. Front Biosci. (2019) 24:545-54. doi: 10.2741/4734

13. Garcia-Carbonero N, Martinez-Useros J, Li W, Orta A, Perez N, Carames C, et al. KRAS and BRAF mutations as prognostic and predictive biomarkers for standard chemotherapy response in metastatic colorectal cancer: a single institutional study. Cells. (2020) 9:219. doi: 10.3390/cells9010219

14. Zemek RM, Chin WL, Nowak AK, Millward MJ, Lake RA, Lesterhuis WJ. Sensitizing the tumor microenvironment to immune checkpoint therapy. Front Immunol. (2020) 11:223. doi: 10.3389/fimmu.2020.00223

15. Li X, Strietz J, Bleilevens A, Stickeler E, Maurer J. Chemotherapeutic stress influences epithelial-mesenchymal transition and stemness in cancer stem cells of triple-negative breast cancer. Int J Mol Sci. (2020) 21:404. doi: 10.3390/ijms21020404

16. Xue S-T, Li K, Gao Y, Zhao L-Y, Gao Y, Yi H, et al. The role of the key autophagy kinase ULK1 in hepatocellular carcinoma and its validation as a treatment target. Autophagy. (2020) 1-15. doi: 10.1080/15548627.2019.1709762. [Epub ahead of print].

17. Robinson K, Tiriveedhi V. Perplexing role of P-glycoprotein in tumor microenvironment. Front Oncol. (2020) 10:265. doi: $10.3389 /$ fonc. 2020.00265

18. Allaire M, Rautou P-E, Codogno P, Lotersztajn S. Autophagy in liver diseases: time for translation? J Hepatol. (2019) 70:985-98. doi: 10.1016/j.jhep.2019.01.026

19. Kimmelman AC, White E. Autophagy and tumor metabolism. Cell Metab. (2017) 25:1037-43. doi: 10.1016/j.cmet.2017.04.004

20. Yu L, Chen Y, Tooze SA. Autophagy pathway: cellular and molecular mechanisms. Autophagy. (2018) 14:207-15. doi: $10.1080 / 15548627.2017 .1378838$

21. Thorburn A. Autophagy and disease. J Biol Chem. (2018) 293:5425-30. doi: $10.1074 /$ jbc.R117.810739

22. Levy JMM, Towers CG, Thorburn A. Targeting autophagy in cancer. Nat Rev Cancer. (2017) 17:528-42. doi: 10.1038/nrc.2017.53

23. Li YJ, Lei YH, Yao N, Wang CR, Hu N, Ye WC, et al. Autophagy and multidrug resistance in cancer. Chin J Cancer. (2017) 36:52. doi: 10.1186/s40880-017-0219-2

24. Choi AM, Ryter SW, Levine B. Autophagy in human health and disease. $N$ Engl J Med. (2013) 368:651-62. doi: 10.1056/NEJMra1205406

25. Shuhua W, Chenbo S, Yangyang L, Xiangqian G, Shuang H, Tangyue L, et al. Autophagy-related genes Raptor, Rictor, and Beclin1 expression and relationship with multidrug resistance in colorectal carcinoma. Hum Pathol. (2015) 46:1752-9. doi: 10.1016/j.humpath.2015.07.016

26. Zhou L, Liu S, Han M, Feng S, Liang J, Li Z, et al. MicroRNA-185 induces potent autophagy via AKT signaling in hepatocellular carcinoma. Tumour Biol. (2017) 39:1010428317694313. doi: 10.1177/1010428317694313

27. Pollutri D, Patrizi C, Marinelli S, Giovannini C, Trombetta E, Giannone FA, et al. The epigenetically regulated miR- 494 associates with stem-cell phenotype and induces sorafenib resistance in hepatocellular carcinoma. Cell Death Dis. (2018) 9:4. doi: 10.1038/s41419-017-0076-6

28. Sun W, Yi Y, Xia G, Zhao Y, Yu Y, Li L, et al. Nrf2-miR-129-3p-mTOR axis controls an miRNA regulatory network involved in HDACi-induced autophagy. Mol Ther. (2019) 27:1039-50. doi: 10.1016/j.ymthe.2019.02.010

29. Zhang K, Chen J, Zhou H, Chen Y, Zhi Y, Zhang B, et al. PU.1/microRNA142-3p targets ATG5/ATG16L1 to inactivate autophagy and sensitize hepatocellular carcinoma cells to sorafenib. Cell Death Dis. (2018) 9:312. doi: 10.1038/s41419-018-0344-0
30. Yuan P, Cao W, Zang Q, Li G, Guo X, Fan J. The HIF-2 $\alpha$-MALAT1-miR-216b axis regulates multi-drug resistance of hepatocellular carcinoma cells via modulating autophagy. Biochem Biophys Res Commun. (2016) 478:1067-73. doi: $10.1016 /$ j.bbrc.2016.08.065

31. Jin F, Wang Y, Li M, Zhu Y, Liang H, Wang C, et al. MiR-26 enhances chemosensitivity and promotes apoptosis of hepatocellular carcinoma cells through inhibiting autophagy. Cell Death Dis. (2017) 8:e2540. doi: 10.1038/cddis.2016.461

32. Xu Y, An Y, Wang Y, Zhang C, Zhang H, Huang C, et al. miR-101 inhibits autophagy and enhances cisplatin-induced apoptosis in hepatocellular carcinoma cells. Oncol Rep. (2013) 29:2019-24. doi: 10.3892/or.2013.2338

33. Xu N, Zhang J, Shen C, Luo Y, Xia L, Xue F, et al. Cisplatin-induced downregulation of miR-199a-5p increases drug resistance by activating autophagy in HCC cell. Biochem Biophys Res Commun. (2012) 423:826-31. doi: 10.1016/j.bbrc.2012.06.048

34. Chang Y, Yan W, He X, Zhang L, Li C, Huang H, et al. miR-375 inhibits autophagy and reduces viability of hepatocellular carcinoma cells under hypoxic conditions. Gastroenterology. (2012) 143:177-87.e8. doi: 10.1053/j.gastro.2012.04.009

35. Zhao P, Li M, Wang Y, Chen Y, He C, Zhang X, et al. Enhancing antitumor efficiency in hepatocellular carcinoma through the autophagy inhibition by miR-375/sorafenib in lipid-coated calcium carbonate nanoparticles. Acta Biomater. (2018) 72:248-55. doi: 10.1016/j.actbio.2018. 03.022

36. Gao AM, Zhang XY, Hu JN, Ke ZP. Apigenin sensitizes hepatocellular carcinoma cells to doxorubic through regulating miR-520b/ATG7 axis. Chem Biol Interact. (2018) 280:45-50. doi: 10.1016/j.cbi.2017.11.020

37. Park YR, Kim SL, Lee MR, Seo SY, Lee JH, Kim SH, et al. MicroRNA-30a-5p (miR-30a) regulates cell motility and EMT by directly targeting oncogenic TM4SF1 in colorectal cancer. J Cancer Res Clin Oncol. (2017) 143:1915-27. doi: 10.1007/s00432-017-2440-4

38. Wu T, Liu Y, Fan Z, Xu J, Jin L, Gao Z, et al. miR-21 Modulates the immunoregulatory function of bone marrow mesenchymal stem cells through the PTEN/Akt/TGF- $\beta 1$ pathway. Stem Cells. (2015) 33:3281-90. doi: $10.1002 /$ stem.2081

39. Bao L, Yan Y, Xu C, Ji W, Shen S, Xu G, et al. MicroRNA-21 suppresses PTEN and hSulf-1 expression and promotes hepatocellular carcinoma progression through AKT/ERK pathways. Cancer Lett. (2013) 337:226-36. doi: 10.1016/j.canlet.2013.05.007

40. He C, Dong X, Zhai B, Jiang X, Dong D, Li B, et al. MiR-21 mediates sorafenib resistance of hepatocellular carcinoma cells by inhibiting autophagy via the PTEN/Akt pathway. Oncotarget. (2015) 6:28867-81. doi: 10.18632/oncotarget.4814

41. Fu XT, Shi YH, Zhou J, Peng YF, Liu WR, Shi GM, et al. MicroRNA30a suppresses autophagy-mediated anoikis resistance and metastasis in hepatocellular carcinoma. Cancer Lett. (2018) 412:108-17. doi: 10.1016/j.canlet.2017.10.012

42. Robey RW, Pluchino KM, Hall MD, Fojo AT, Bates SE, Gottesman MM. Revisiting the role of $\mathrm{ABC}$ transporters in multidrug-resistant cancer. Nat Rev Cancer. (2018) 18:452-64. doi: 10.1038/s41568-018-0005-8

43. Domenichini A, Adamska A, Falasca M. ABC transporters as cancer drivers: Potential functions in cancer development. Biochim Biophys Acta Gen Subj. (2019) 1863:52-60. doi: 10.1016/j.bbagen.2018.09.019

44. Paula Ceballos M, Pablo Rigalli J, Ines Cere L, Semeniuk M, Alicia Catania V, Laura Ruiz M. ABC transporters: regulation and association with multidrug resistance in hepatocellular carcinoma and colorectal carcinoma. Curr Med Chem. (2019) 26:1224-50. doi: 10.2174/0929867325666180105103637

45. Silva N, Salgueiro L, Fortuna A, Cavaleiro C. P-glycoprotein mediated efflux modulators of plant origin: a short review. Nat Prod Commun. (2016) 11:699-704. doi: 10.1177/1934578X1601100538

46. Breier A, Gibalova L, Seres M, Barancik M, Sulova Z. New insight into pglycoprotein as a drug target. Anticancer Agents Med Chem. (2013) 13:15970. doi: $10.2174 / 187152013804487380$

47. Chen Z, Shi T, Zhang L, Zhu P, Deng M, Huang C, et al. Mammalian drug efflux transporters of the ATP binding cassette (ABC) family in multidrug resistance: a review of the past decade. Cancer Lett. (2016) 370:153-64. doi: 10.1016/j.canlet.2015.10.010

48. Sharom FJ. ABC multidrug transporters: structure, function and role in chemoresistance. Pharmacogenomics. (2008) 9:105-27. doi: $10.2217 / 14622416.9 .1 .105$ 
49. Xu Y, Ohms SJ, Li Z, Wang Q, Gong G, Hu Y, et al. Changes in the expression of miR-381 and miR-495 are inversely associated with the expression of the MDR1 gene and development of multi-drug resistance. PLoS One. (2013) 8:e82062. doi: 10.1371/journal.pone.0082062

50. Messingerova L, Imrichova D, Kavcova H, Seres M, Sulova Z, Breier A. A decrease in cellular microRNA-27a content is involved in azacytidineinduced P-glycoprotein expression in SKM-1 cells. Toxicol In Vitro. (2016) 36:81-8. doi: 10.1016/j.tiv.2016.07.002

51. Yang $\mathrm{T}$, Zheng ZM, Li XN, Li ZF, Wang Y, Geng YF, et al. MiR223 modulates multidrug resistance via downregulation of $\mathrm{ABCB} 1$ in hepatocellular carcinoma cells. Exp Biol Med. (2013) 238:1024-32. doi: $10.1177 / 1535370213497321$

52. Ding L, Ni J, Yang F, Huang L, Deng H, Wu Y, et al. Promising therapeutic role of miR-27b in tumor. Tumour Biol. (2017) 39:1010428317691657. doi: $10.1177 / 1010428317691657$

53. Chen Z, Ma T, Huang C, Zhang L, Lv X, Xu T, et al. MiR-27a modulates the MDR1/P-glycoprotein expression by inhibiting FZD7/beta-catenin pathway in hepatocellular carcinoma cells. Cell Signal. (2013) 25:2693-701. doi: 10.1016/j.cellsig.2013.08.032

54. Stefan SM, Wiese M. Small-molecule inhibitors of multidrug resistanceassociated protein 1 and related processes: a historic approach and recent advances. Med Res Rev. (2019) 39:176-264. doi: 10.1002/med.21510

55. Painefilu JC, Pascual MM, Bieczynski F, Laspoumaderes C, Gonzalez C, Villanueva SSM, et al. Ex vivo and in vivo effects of arsenite on GST and $\mathrm{ABCC} 2$ activity and expression in the middle intestine of the rainbow trout Oncorhynchus mykiss. Comp Biochem Physiol Pt C Toxicol Pharmacol. (2019) 225:108566. doi: 10.1016/j.cbpc.2019.108566

56. Bruhn O, Lindsay M, Wiebel F, Kaehler M, Nagel I, Boehm R, et al. Alternative polyadenylation of $\mathrm{ABC}$ transporters of the $\mathrm{C}$-family (ABCC1, $\mathrm{ABCC} 2, \mathrm{ABCC} 3)$ and implications on posttranscriptional micro-RNA regulation. Mol Pharmacol. (2020) 97:112-22. doi: 10.1124/mol.119.1 16590

57. Ma J, Wang $\mathrm{T}$, Guo $\mathrm{R}$, Yang $\mathrm{X}$, Yin $\mathrm{J}$, $\mathrm{Yu} \mathrm{J}$, et al. Involvement of miR-133a and miR-326 in ADM resistance of HepG2 through modulating expression of ABCC1. J Drug Target. (2015) 23:519-24. doi: 10.3109/1061186X.2015.1015536

58. Werk AN, Bruckmueller H, Haenisch S, Cascorbi I. Genetic variants may play an important role in mRNA-miRNA interaction: evidence for haplotype-dependent downregulation of ABCC2 (MRP2) by miRNA-379. Pharmacogenet Genomics. (2014) 24:283-91. doi: 10.1097/FPC.0000000000000046

59. Cai Z, Cao Y, Luo Y, Hu H, Ling H. Signalling mechanism(s) of epithelial-mesenchymal transition and cancer stem cells in tumour therapeutic resistance. Clin Chim Acta. (2018) 483:156-63. doi: 10.1016/j.cca.2018.04.033

60. Lamouille S, Xu J, Derynck R. Molecular mechanisms of epithelialmesenchymal transition. Nat Rev Mol Cell Biol. (2014) 15:178-96. doi: $10.1038 / \mathrm{nrm} 3758$

61. Nieto MA, Huang RY, Jackson RA, Thiery JP. EMT: 2016. Cell. (2016) 166:21-45. doi: 10.1016/j.cell.2016.06.028

62. Thiery JP, Acloque H, Huang RY, Nieto MA. Epithelial-mesenchymal transitions in development and disease. Cell. (2009) 139:871-90. doi: 10.1016/j.cell.2009.11.007

63. Chen T, You Y, Jiang H, Wang ZZ. Epithelial-mesenchymal transition (EMT): a biological process in the development, stem cell differentiation, and tumorigenesis. J Cell Physiol. (2017) 232:3261-72. doi: 10.1002/jcp.25797

64. Mani SA, Guo W, Liao MJ, Eaton EN, Ayyanan A, Zhou AY, et al. The epithelial-mesenchymal transition generates cells with properties of stem cells. Cell. (2008) 133:704-15. doi: 10.1016/j.cell.2008.03.027

65. Shibue T, Weinberg RA. EMT, CSCs, and drug resistance: the mechanistic link and clinical implications. Nat Rev Clin Oncol. (2017) 14:611-29. doi: $10.1038 /$ nrclinonc.2017.44

66. Ebert MS, Sharp PA. Roles for microRNAs in conferring robustness to biological processes. Cell. (2012) 149:515-24. doi: 10.1016/j.cell.2012.04.005

67. Ghahhari NM, Babashah S. Interplay between microRNAs and WNT/betacatenin signalling pathway regulates epithelial-mesenchymal transition in cancer. Eur J Cancer. (2015) 51:1638-49. doi: 10.1016/j.ejca.2015.04.021

68. Mutlu M, Raza U, Saatci O, Eyupoglu E, Yurdusev E, Sahin O. miR-200c: a versatile watchdog in cancer progression, EMT, and drug resistance. J Mol Med (Berl). (2016) 94:629-44. doi: 10.1007/s00109-016-1420-5
69. Wellner U, Schubert J, Burk UC, Schmalhofer O, Zhu F, Sonntag A, et al. The EMT-activator ZEB1 promotes tumorigenicity by repressing stemness-inhibiting microRNAs. Nat Cell Biol. (2009) 11:1487-95. doi: 10.1038/ncb1998

70. Liu Y, Li Y, Wang R, Qin S, Liu J, Su F, et al. MiR-130a-3p regulates cell migration and invasion via inhibition of Smad4 in gemcitabine resistant hepatoma cells. J Exp Clin Cancer Res. (2016) 35:19. doi: 10.1186/s13046-016-0296-0

71. Wang R, Li Y, Hou Y, Yang Q, Chen S, Wang X, et al. The PDGF$\mathrm{D} / \mathrm{miR}-106 \mathrm{a} /$ Twistl pathway orchestrates epithelial-mesenchymal transition in gemcitabine resistance hepatoma cells. Oncotarget. (2015) 6:7000-10. doi: 10.18632/oncotarget.3193

72. Jin Y, Wang J, Han J, Luo D, Sun Z. MiR-122 inhibits epithelial-mesenchymal transition in hepatocellular carcinoma by targeting Snail1 and Snail2 and suppressing WNT/beta-cadherin signaling pathway. Exp Cell Res. (2017) 360:210-7. doi: 10.1016/j.yexcr.2017.09.010

73. Xia W, Ma X, Li X, Dong H, Yi J, Zeng W, et al. miR-153 inhibits epithelialto-mesenchymal transition in hepatocellular carcinoma by targeting Snail. Oncol Rep. (2015) 34:655-62. doi: 10.3892/or.2015.4008

74. Wang R, Fu T, You K, Li S, Zhao N, Yang J, et al. Identification of a TGFbeta-miR-195 positive feedback loop in hepatocytes and its deregulation in hepatoma cells. Faseb J. (2018) 32:3936-45. doi: 10.1096/fj.201701199R

75. Cao F, Yin LX. miR-122 enhances sensitivity of hepatocellular carcinoma to oxaliplatin via inhibiting MDR1 by targeting Wnt/beta-catenin pathway. Exp Mol Pathol. (2019) 106:34-43. doi: 10.1016/j.yexmp.2018.10.009

76. Chen L, Gibbons DL, Goswami S, Cortez MA, Ahn YH, Byers LA, et al. Metastasis is regulated via microRNA-200/ZEB1 axis control of tumour cell PD-L1 expression and intratumoral immunosuppression. Nat Commun. (2014) 5:5241. doi: 10.1038/ncomms6241

77. Wu T, Dai Y. Tumor microenvironment and therapeutic response. Cancer Lett. (2017) 387:61-8. doi: 10.1016/j.canlet.2016.01.043

78. Scott DW, Gascoyne RD. The tumour microenvironment in B cell lymphomas. Nat Rev Cancer. (2014) 14:517-34. doi: 10.1038/nrc3774

79. Raggi C, Invernizzi P, Andersen JB. Impact of microenvironment and stemlike plasticity in cholangiocarcinoma: molecular networks and biological concepts. J Hepatol. (2015) 62:198-207. doi: 10.1016/j.jhep.2014.09.007

80. Ruffell B, Coussens LM. Macrophages and therapeutic resistance in cancer. Cancer Cell. (2015) 27:462-72. doi: 10.1016/j.ccell.2015.02.015

81. Schulte L-A, Lopez-Gil JC, Sainz B Jr, Hermann PC. The cancer stem cell in hepatocellular carcinoma. Cancers. (2020) 12:684. doi: $10.3390 /$ cancers 12030684

82. Lytle NK, Barber AG, Reya T. Stem cell fate in cancer growth, progression and therapy resistance. Nat Rev Cancer. (2018) 18:669-80. doi: 10.1038/s41568-018-0056-x

83. Arnold CR, Mangesius J, Skvortsova I-I, Ganswindt U. The role of cancer stem cells in radiation resistance. Front Oncol. (2020) 10:164. doi: $10.3389 /$ fonc. 2020.00164

84. Wu Y, Zhang J, Zhang X, Zhou H, Liu G, Li Q. Cancer stem cells: a potential breakthrough in HCC-targeted therapy. Front Pharmacol. (2020) 11:198. doi: 10.3389/fphar.2020.00198

85. Lou W, Liu J, Gao Y, Zhong G, Ding B, Xu L, et al. MicroRNA regulation of liver cancer stem cells. Am J Cancer Res. (2018) 8:1126-41.

86. Zhu CP, Wang AQ, Zhang HH, Wan XS, Yang XB, Chen SG, et al. Research progress and prospects of markers for liver cancer stem cells. World $J$ Gastroenterol. (2015) 21:12190-6. doi: 10.3748/wjg.v21.i42.12190

87. Jin B, Wang W, Meng XX, Du G, Li J, Zhang SZ, et al. Let-7 inhibits self-renewal of hepatocellular cancer stem-like cells through regulating the epithelial-mesenchymal transition and the Wnt signaling pathway. $B M C$ Cancer. (2016) 16:863. doi: 10.1186/s12885-016-2904-y

88. Feng X, Jiang J, Shi S, Xie H, Zhou L, Zheng S. Knockdown of miR25 increases the sensitivity of liver cancer stem cells to TRAIL-induced apoptosis via PTEN/PI3K/Akt/Bad signaling pathway. Int J Oncol. (2016) 49:2600-10. doi: 10.3892/ijo.2016.3751

89. Liu Q, Xu Y, Wei S, Gao W, Chen L, Zhou T, et al. miRNA-148b suppresses hepatic cancer stem cell by targeting neuropilin-1. Biosci Rep. (2015) 35:e00229. doi: 10.1042/BSR20150084

90. Zhou JN, Zeng Q, Wang HY, Zhang B, Li ST, Nan X, et al. MicroRNA$125 \mathrm{~b}$ attenuates epithelial-mesenchymal transitions and targets stem-like liver cancer cells through small mothers against decapentaplegic 2 and 4 . Hepatology. (2015) 62:801-15. doi: 10.1002/hep.27887 
91. Petrova V, Annicchiarico-Petruzzelli M, Melino G, Amelio I. The hypoxic tumour microenvironment. Oncogenesis. (2018) 7:10. doi: 10.1038/s41389-017-0011-9

92. Balamurugan K. HIF-1 at the crossroads of hypoxia, inflammation, and cancer. Int J Cancer. (2016) 138:1058-66. doi: 10.1002/ijc.29519

93. D'Ignazio L, Bandarra D, Rocha S. NF- $\kappa$ B and HIF crosstalk in immune responses. FEBS J. (2016) 283:413-24. doi: 10.1111/febs. 13578

94. Xu H, Zhao L, Fang Q, Sun J, Zhang S, Zhan C, et al. MiR-338-3p inhibits hepatocarcinoma cells and sensitizes these cells to sorafenib by targeting hypoxia-induced factor 1alpha. PLoS One. (2014) 9:e115565. doi: 10.1371/journal.pone.0115565

95. Qiu Y, Shan W, Yang Y, Jin M, Dai Y, Yang H, et al. Reversal of sorafenib resistance in hepatocellular carcinoma: epigenetically regulated disruption of 14-3-3eta/hypoxia-inducible factor-1 $\alpha$. Cell Death Discov. (2019) 5:120. doi: 10.1038/s41420-019-0200-8

96. Noman MZ, Buart S, Romero P, Ketari S, Janji B, Mari B, et al. Hypoxia-inducible miR-210 regulates the susceptibility of tumor cells to lysis by cytotoxic T cells. Cancer Res. (2012) 72:4629-41. doi: 10.1158/0008-5472.CAN-12-1383

97. Vander Heiden MG, Cantley LC, Thompson CB. Understanding the Warburg effect: the metabolic requirements of cell proliferation. Science. (2009) 324:1029-33. doi: 10.1126/science.1160809

98. Lu J, Tan M, Cai Q. The Warburg effect in tumor progression: mitochondrial oxidative metabolism as an anti-metastasis mechanism. Cancer Lett. (2015) 356(2 Pt A):156-64. doi: 10.1016/j.canlet.2014.04.001

99. San-Millan I, Brooks GA. Reexamining cancer metabolism: lactate production for carcinogenesis could be the purpose and explanation of the Warburg Effect. Carcinogenesis. (2017) 38:119-33. doi: 10.1093/carcin/bgw127

100. Chan AK, Bruce JI, Siriwardena AK. Glucose metabolic phenotype of pancreatic cancer. World J Gastroenterol. (2016) 22:3471-85. doi: 10.3748/wjg.v22.i12.3471

101. Zhang C, Liu J, Liang Y, Wu R, Zhao Y, Hong X, et al. Tumour-associated mutant p53 drives the Warburg effect. Nat Commun. (2013) 4:2935. doi: $10.1038 /$ ncomms3935

102. Liu W, Kang L, Han J, Wang Y, Shen C, Yan Z, et al. miR-342-3p suppresses hepatocellular carcinoma proliferation through inhibition of IGF-1R-mediated Warburg effect. Onco Targets Ther. (2018) 11:1643-53. doi: 10.2147/OTT.S161586

103. Han H, Li W, Shen H, Zhang J, Zhu Y, Li Y. microRNA-129-5p, a c-Myc negative target, affects hepatocellular carcinoma progression by blocking the Warburg effect. J Mol Cell Biol. (2016) 8:400-10. doi: 10.1093/jmcb/mjw010

104. Jiang JX, Gao S, Pan YZ, Yu C, Sun CY. Overexpression of microRNA-125b sensitizes human hepatocellular carcinoma cells to 5-fluorouracil through inhibition of glycolysis by targeting hexokinase II. Mol Med Rep. (2014) 10:995-1002. doi: 10.3892/mmr.2014.2271

105. Song K, Kwon H, Han C, Zhang J, Dash S, Lim K, et al. Active glycolytic metabolism in $\mathrm{CD}_{133^{+}}$hepatocellular cancer stem cells: regulation by MIR122. Oncotarget. (2015) 6:40822-35. doi: 10.18632/oncotarget.5812

106. Johnstone RW, Ruefli AA, Lowe SW. Apoptosis: a link between cancer genetics and chemotherapy. Cell. (2002) 108:153-64. doi: 10.1016/S0092-8674(02)00625-6

107. Reed JC, Miyashita T, Takayama S, Wang HG, Sato T, Krajewski S, et al. BCL-2 family proteins: regulators of cell death involved in the pathogenesis of cancer and resistance to therapy. J Cell Biochem. (1996) 60:23-32. doi: 10.1002/(SICI)1097-4644(19960101)60:1<23::AID-JCB5>3.0.CO;2-5

108. Davids MS. Targeting BCL-2 in B-cell lymphomas. Blood. (2017) 130:1081-8. doi: 10.1182/blood-2017-04-737338

109. Garcia-Aranda M, Perez-Ruiz E, Redondo M. Bcl-2 inhibition to overcome resistance to chemo- and immunotherapy. Int J Mol Sci. (2018) 19:3950. doi: 10.3390/ijms19123950

110. Zhu C, Zhou R, Zhou Q, Chang Y, Jiang M. microRNA-539 suppresses tumor growth and tumorigenesis and overcomes arsenic trioxide resistance in hepatocellular carcinoma. Life Sci. (2016) 166:34-40. doi: 10.1016/j.lfs.2016.10.002

111. Yang F, Li QJ, Gong ZB, Zhou L, You N, Wang S, et al. MicroRNA34a targets $\mathrm{Bcl}-2$ and sensitizes human hepatocellular carcinoma cells to sorafenib treatment. Technol Cancer Res Treat. (2014) 13:77-86. doi: 10.7785/tcrt.2012.500364

112. Ou Y, Zhai D, Wu N, Li X. Downregulation of miR-363 increases drug resistance in cisplatin-treated HepG2 by dysregulating Mcl-1. Gene. (2015) 572:116-22. doi: 10.1016/j.gene.2015.07.002

113. Song MS, Salmena L, Pandolfi PP. The functions and regulation of the PTEN tumour suppressor. Nat Rev Mol Cell Biol. (2012) 13:283-96. doi: $10.1038 / \mathrm{nrm} 3330$

114. Lee YR, Chen M, Pandolfi PP. The functions and regulation of the PTEN tumour suppressor: new modes and prospects. Nat Rev Mol Cell Biol. (2018) 19:547-62. doi: 10.1038/s41580-018-0015-0

115. Milella M, Falcone I, Conciatori F, Cesta Incani U, Del Curatolo A, Inzerilli $\mathrm{N}$, et al. PTEN: multiple functions in human malignant tumors. Front Oncol. (2015) 5:24. doi: 10.3389/fonc.2015.00024

116. Ersahin T, Tuncbag N, Cetin-Atalay R. The PI3K/AKT/mTOR interactive pathway. Mol Biosyst. (2015) 11:1946-54. doi: 10.1039/C5MB00101C

117. Carnero A, Blanco-Aparicio C, Renner O, Link W, Leal JF. The PTEN/PI3K/AKT signalling pathway in cancer, therapeutic implications. Curr Cancer Drug Targets. (2008) 8:187-98. doi: 10.2174/156800908784293659

118. Jiang XM, Yu XN, Liu TT, Zhu HR, Shi X, Bilegsaikhan E, et al. microRNA-19a-3p promotes tumor metastasis and chemoresistance through the PTEN/Akt pathway in hepatocellular carcinoma. Biomed Pharmacother. (2018) 105:1147-54. doi: 10.1016/j.biopha.2018.06.097

119. Xia H, Ooi LL, Hui KM. MicroRNA-216a/217-induced epithelialmesenchymal transition targets PTEN and SMAD7 to promote drug resistance and recurrence of liver cancer. Hepatology. (2013) 58:629-41. doi: 10.1002/hep.26369

120. Shao P, Qu WK, Wang CY, Tian Y, Ye ML, Sun DG, et al. MicroRNA-205-5p regulates the chemotherapeutic resistance of hepatocellular carcinoma cells by targeting PTEN/JNK/ANXA3 pathway. Am J Transl Res. (2017) 9:4300-7.

121. Tian T, Fu X, Lu J, Ruan Z, Nan K, Yao Y, et al. MicroRNA-760 inhibits doxorubicin resistance in hepatocellular carcinoma through regulating notch1/hes1-PTEN/Akt signaling pathway. J Biochem Mol Toxicol. (2018) 32:e22167. doi: 10.1002/jbt.22167

122. Kranenburg O. The KRAS oncogene: past, present, and future. Biochim Biophys Acta Rev Cancer. (2005) 1756:81-2. doi: 10.1016/j.bbcan.2005.10.001

123. Roncarati R, Lupini L, Shankaraiah RC, Negrini M. The importance of microRNAs in RAS oncogenic activation in human cancer. Front Oncol. (2019) 9:988. doi: 10.3389/fonc.2019.00988

124. Dietrich P, Koch A, Fritz V, Hartmann A, Bosserhoff AK, Hellerbrand C. Wild type Kirsten rat sarcoma is a novel microRNA-622-regulated therapeutic target for hepatocellular carcinoma and contributes to sorafenib resistance. Gut. (2018) 67:1328-41. doi: 10.1136/gutjnl-2017-315402

125. Chen K-j, Hou Y, Wang K, Li J, Xia Y, Yang X-y, et al. Reexpression of Let-7g MicroRNA Inhibits the proliferation and migration via K-Ras/HMGA2/snail axis in hepatocellular carcinoma. Biomed Res Int. (2014) 2014:742417. doi: $10.1155 / 2014 / 742417$

126. Gnoni A, Licchetta A, Memeo R, Argentiero A, Solimando AG, Longo $\mathrm{V}$, et al. Role of BRAF in hepatocellular carcinoma: a rationale for future targeted cancer therapies. Medicina. (2019) 55:754. doi: 10.3390/medicina55120754

127. Choe MH, Yoon Y, Kim J, Hwang S-G, Han Y-H, Kim J-S. miR-550a3-5p acts as a tumor suppressor and reverses BRAF inhibitor resistance through the direct targeting of YAP. Cell Death Dis. (2018) 9:640. doi: 10.1038/s41419-018-0698-3

Conflict of Interest: The authors declare that the research was conducted in the absence of any commercial or financial relationships that could be construed as a potential conflict of interest.

Copyright (c) 2020 Liang, Liang, Qiao and Xiao. This is an open-access article distributed under the terms of the Creative Commons Attribution License (CC BY). The use, distribution or reproduction in other forums is permitted, provided the original author(s) and the copyright owner(s) are credited and that the original publication in this journal is cited, in accordance with accepted academic practice. No use, distribution or reproduction is permitted which does not comply with these terms. 